\title{
Profil supplementary scales Minnesota multiphasic personality inventory-2 (MMPI-2) adaptasi Indonesia pada komunitas public united not kingdom (punk) di kawasan Megamas Kota Manado
}

\author{
${ }^{1}$ Rijal Ab'ror \\ ${ }^{2}$ Bernabas H. R. Kairupan \\ ${ }^{2}$ Herdy Munayang
}

\author{
${ }^{1}$ Kandidat Skripsi Fakultas Kedokteran Universitas Sam Ratulangi Manado \\ ${ }^{2}$ Bagian Psikiatri Fakultas Kedokteran Universitas Sam Ratulangi \\ Email: rijallabror@gmail.com
}

\begin{abstract}
Society in general still views punk community negatively. It is caused by their dress and hair styles which were assumed as weird, therefore, they are considered dangerous for other citizens. This study was aimed to examine mental health status of members of punk community for detection of the presence of any mental disorders. This was a survey study with a crosssectional design to determine the members of punk community mental status at Megamas area in Manado based on Supplementary Scales of Minnesota Multiphasic Personality Inventory-2 (MMPI-2) Indonesian adaptation. According to socio-demographic data the majority of 30 respondents were males $(86.67 \%)$, age range $18-27$ years old $(86.67 \%)$, respondents' parents worked as private sectors employees $(50 \%)$, respondents worked in private sectors $(70 \%)$, had three siblings (43.33\%), lived in Manado (76.67\%), senior high school graduates (83.33\%), reason of joining punk community was freedom (63,33\%). Supplementary scales of MMPI-2 distribution obtained high t-score to low t-score as follows: PK (83.33\%), AAS (56.67\%), MAC-R (46.67\%), A (46.67\%), MDS (43.33\%), Ho (36.67\%), Mt (30\%), OH (6.67\%), R (3.33\%), Es $(0 \%)$, Do $(0 \%)$, Re (0\%), APS (0\%), GM (0\%), and GF (0\%). Conclusion: The supplementary scales of MMPI-2 Indonesian adaptation in punk community at Megamas area in Manado city obtained high t-scores in Post Traumatic Disorder, Addiction Acknowledge/Admission Scale, MacAndrew Alcoholism-Revised, Anxiety Scale, Marital Distress, and Hostility Scales.

Keywords: profile, supplementary scales, MMPI-2 Indonesian adaptation, punk community
\end{abstract}

\begin{abstract}
Abstrak: Masyarakat umumnya masih memandang komunitas punk dengan pandangan negatif dikarenakan gaya berpakaian dan gaya rambut yang aneh serta dianggap sebagai komunitas yang berbahaya. Penelitian ini bertujuan untuk mendapatkan status kesehatan mental pada anggota komunitas punk untuk mendeteksi adanya gangguan mental. Jenis penelitian ialah survey dengan desain potong lintang untuk mengetahui status mental anggota komunitas punk di kawasan Megamas Kota Manado berdasarkan Supplementary Scales Minnesota Multiphasic Personality Inventory-2 (MMPI-2) adaptasi Indonesia. Berdasarkan sosio-demografi dari 30 responden, distribusi anggota komunitas punk terbanyak ialah laki-laki $(86,67 \%)$, rentang usia 18-27 tahun (86,67\%), pekerjaan orang tua responden di bidang swasta (50\%), pekerjaan responden di bidang swasta (70\%), memiliki jumlah saudara sebanyak tiga orang $(43,33 \%)$, beralamat di Kota Manado (76,67\%), pendidikan terakhir SMA (83,33\%), dan alasan bergabung pada komunitas punk karena menginginkan kebebasan (63,33\%). Hasil distribusi supplementary scales MMPI-2, mendapatkan skala dengan t-skor yang tinggi dengan persentase berturut-turut dari tinggi ke rendah yaitu: PK (83,33\%), AAS (56,67\%), MAC-R (46,67\%), A (46,67\%), MDS $(43,33 \%)$, Ho $(36,67 \%)$, Mt (30\%), OH (6,67\%), R (3,33\%), Es $(0 \%)$, Do $(0 \%), \operatorname{Re}(0 \%)$,APS $(0 \%)$, GM (0\%), dan GF (0\%). Simpulan: Supplementary Scales Minnesota Multiphasic Personality Inventory-2 (MMPI-2) adaptasi Indonesia yang tinggi yaitu pada Post Traumatic Disorder, Addiction Acknowledge/Admission Scale, MacAndrew Alkhoholism-Revised, Anxiety Scale, Marital Distress dan Hostility Scales.
\end{abstract}

Kata kunci: profil, supplementary scales, MMPI-2 adaptasi indonesia, komunitas punk 
Punk pertama kali muncul di Inggris sebagai gerakan perlawanan kelompok pekerja muda karena dipicu oleh bobrok dan korupnya pemerintahan saat itu. ${ }^{1}$ Pada tahun 1977 keberadaan komunitas ini mulai menyebar ke Amerika dan ke seluruh dunia. ${ }^{2}$ Punk menganut ideologi pemberontakan dan anti kemapanan, dengan berbagai macam karakter dari tiap anggota. ${ }^{3}$

Punk masuk di Indonesia pada akhir tahun 1980 dan berkembang pesat pada pertengahan 1990 karena terjadi kesenjangan sosial yang sangat tajam, pendidikan yang rendah, tingkat pengangguran dan buta huruf yang tinggi di kalangan pemuda. ${ }^{4}$ Komunitas punk tersebar di berbagai wilayah seperti: Jakarta, Bandung, Surabaya, Aceh, Samarinda, Malang, dan lain-lain. ${ }^{5}$ Tempat terbuka dan ramai ialah tempat komunitas punk berkumpul seperti: alunalun, perempatan jalan, lampu lalu lintas, dan lain-lain. ${ }^{3}$

Kota Manado ialah ibukota provinsi Sulawesi Utara dengan pertumbuhan ekonomi yang cukup tinggi. ${ }^{6}$ Kawasan Megamas merupakan pusat perbelanjaan, perkantoran, hiburan, dan rekreasi di Kota Manado. Berdasarkan observasi peneliti komunitas punk biasa berkumpul di Kawasan Megamas, khususnya pada bangunan kosong dan pesisir pantai di depan indomaret point, suatu tempat di pesisir pantai kawasan Megamas yang berada di depan indomaret, KFC,dan MC Donald.

Komunitas punk dikenal dari gaya berpakaian dan gaya rambut yang khas seperti: sepatu boots, potongan rambut mohawk ala suku Indian, atau dipotong ala feathercut dan diwarnai dengan warnawarna terang, rantai, jaket kulit, celana jeans ketat, spike (gelang duri) baju lusuh anti kemapanan, antisosial. ${ }^{1,4,7,8}$ Sehingga banyak yang beranggapan bahwa seseorang dengan penampilan seperti itu sudah layak disebut punker. ${ }^{1,7}$

Penampilan komunitas punk menciptakan stigma buruk yang berkembang di masyarakat bahwa punk sering dikaitkan dengan perbuatan negatif yang berisiko tinggi meresahkan masyarakat, ${ }^{1,5,9}$ misalnya mengonsumsi minuman beralkohol, menjadi pecandu narkoba, pelaku seks bebas, melakukan tindakan kriminal, melakukan perusakan terhadap sarana umum, dan menyebabkan kekacauan di jalan. ${ }^{5}$

MMPI-2 merupakan salah satu pemeriksaan kesehatan mental untuk mengetahui fungsi kepribadian, keadaan emosional, keparahan psikopatologi, serta dapat merumuskan tindakan/pengobatan. MMPI-2 digunakan secara luas di seluruh dunia untuk meneliti status kesehatan mental seseorang. ${ }^{10-13}$ MMPI-2 dikenal sebagai alat ukur kepribadian dan kondisi psikopatologis yang objektif, artinya hasil interpretasi sesuai dengan penilaian yang dilaporkan oleh responden sendiri (selfreport). ${ }^{11}$ Instrumen psikometrik ini juga dapat mendeteksi kumpulan respons yang diinginkan seseorang secara sosial sehingga dapat terlihat seseorang yang berusaha menampilkan dirinya dalam pandangan menyenangkan atau sebaliknya berpurapura sedih. ${ }^{13}$ Terdapat skala-skala yang digunakan dalam MMPI-2 antara lain: validity scales, basic scales, content scales, dan supplementary scales. Setiap skala memiliki fungsi dan tujuan masing-masing. Untuk mengetahui dan menilai adanya potensi psikopatologi pada seseorang dapat dilihat pada supplementary scales. ${ }^{14}$ Dalam supplementary scales terdapat 15 skala; masing-masing skala memiliki nilai yang digunakan untuk menilai potensi psikopatologi seseorang. ${ }^{12-14}$

Dengan stigma yang berkembang di masyarakat tersebut, peneliti tertarik untuk mengetahui lebih dalam mengenai komunitas punk di Kota Manado khususnya di kawasan Megamas. Peneliti ingin mengetahui gambaran kepribadian yang dimiliki oleh anggota komunitas punk dengan menilai potensi gangguan kejiwaan menggunakan Minnesota Multiphasic Personality Inventory-2 (MMPI-2) adaptasi Indonesia. 


\section{METODE PENELITIAN}

Jenis penelitian ini ialah deskriptif dengan melakukan survei potong lintang. Pad penelitian ini diberikan kuesioner kepada anggota komunitas punk di kawasan Megamas kota Manado, dan dilaksanakan dalam periode bulan September - Oktober 2016. Populasi ialah seluruh anggota komunitas punk yang memenuhi kriteria inklusi (termasuk anggota komunitas punk yang bersedia menjadi responden dan juga berusia di atas 18 tahun) dan eksklusi (tidak bisa baca tulis dan juga tidak bisa hadir pada saat pengisian kuesioner). Terdapat sebanyak 33 orang yang hadir mengikuti tes MMPI-2 sedangkan hasil tes MMPI-2 yang valid sebanyak 30 orang.

Variabel dari penelitian ini yaitu supplementary scales dan sosio-demografik (jenis kelamin, usia, pekerjaan orang tua, pekerjaan sehari-hari, jumlah saudara, alamat, pendidikan terakhir, dan alasan bergabung dengan komunitas punk).

Data yang telah terkumpul diolah dan dianalisis dengan menggunakan analisis univariat. Data supplementary scales MMPI-2 diserahkan pada pemeriksa untuk menginterpretasikan MMPI-2 yang diolah oleh program khusus. Untuk mengelola data sosio-demografi dan data hasil interpretasi MMPI-2 digunakan program Microsorft Excel.

\section{HASIL PENELITIAN}

Terdapat 30 responden yang memiliki hasil valid. Data yang ditampilkan dibawah ini merupakan tiga skala yang memiliki nilai t-skor tertinggi dari supplementary scales MMPI-2 pada anggota komunitas punk dengan menggunakan cut off score $<40$ rendah, 40-65 normal/rata-rata, dan $>65$ tinggi.

Tabel 1 menunjukkan dari 30 hasil yang yang valid terdapat 25 responden yang memiliki skor tinggi pada skala Post Traumatic Disorder (PK), terdiri dari 21 responden laki-laki dan 4 responden perempuan. Terdapat 17 responden yang memiliki skor tinggi pada skala Addiction Admission Scale (AAS), terdiri dari 14 responden laki-laki dan 3 responden perempuan, sedangkan skala MacAndrew Alcoholism Scale Revised (MAC-R) terdapat 14 responden yang memiliki skor tinggi, terdiri dari 11 responden laki-laki dan 3 responden perempuan.

Tabel 1. Distribusi responden berdasarkan jenis kelamin dan hasil tinggi pada Supplementary Scales

\begin{tabular}{ccccc}
\hline $\begin{array}{c}\text { Jenis } \\
\text { Kelamin }\end{array}$ & N & PK & AAS & MAC-R \\
\hline \multirow{2}{*}{ Laki-laki } & 26 & 21 & 14 & 11 \\
& $86,67 \%$ & $70 \%$ & $46,67 \%$ & $36,67 \%$ \\
Perempuan & 4 & 4 & 3 & 3 \\
& $13,33 \%$ & $13,33 \%$ & $10 \%$ & $10 \%$ \\
TOTAL & 30 & 25 & 17 & 14 \\
& & $83,33 \%$ & $56,67 \%$ & $46,67 \%$ \\
\hline
\end{tabular}

Tabel 2 menunjukkan dari 30 data valid terdapat 25 responden yang memiliki skor tinggi pada skala Post Traumatic Disorder (PK), terdiri dari 4 responden yang memiliki pendidikan terakhir hingga SMP dan 21 responden yang memiliki pendidikan terakhir hingga SMA. terdapat 17 responden yang memiliki skor tinggi pada skala Addiction Admission Scale (AAS), terdiri dari 2 responden yang pendidikan terakhir hingga SMP dan 15 responden yang pendidikan terakhir hingga SMA, sedangkan pada skala MacAndrew Alcoholism Scale Revised (MAC-R) terdapat 14 responden yang memiliki skor tinggi, terdiri dari 2 responden yang pendidikan terakhir hingga SMP dan 12 responden yang pendidikan terakhir hingga SMA.

Tabel 3 menunjukkan bahwa dari 30 data valid terdapat 25 responden yang memiliki skor tinggi pada skala Post Traumatic Disorder (PK), terdiri dari 20 responden yang bertempat tinggal di Manado dan 5 responden yang bertempat tinggal di luar Manado. Terdapat 17 responden yang memiliki skor tinggi pada skala Addiction Admission Scale(AAS), terdiri dari 14 responden yang bertempat 
tinggal di Manado dan 3 responden yang bertempat tinggal di luar Manado. Sedangkan pada skala MacAndrew Alcoholism Scale Revised (MAC-R) terdapat 14 responden yang memilki skor tinggi yang terdiri dari 12 responden yang bertempat tinggal di Manado dan 2 responden yang bertempat tinggal di luar Manado.

Tabel 2. Distribusi responden berdasarkan pendidikan terakhir dan hasil tinggi pada Supplementary Scales

\begin{tabular}{ccccc}
\hline $\begin{array}{c}\text { Pendidikan } \\
\text { Terakhir }\end{array}$ & $\mathrm{N}$ & $\mathrm{PK}$ & AAS & MACR \\
\hline SD & 0 & 0 & 0 & 0 \\
& & $0 \%$ & $0 \%$ & $0 \%$ \\
SMP & 5 & 4 & 2 & 2 \\
& $16,67 \%$ & $13,33 \%$ & $6,67 \%$ & $6,67 \%$ \\
SMA & 25 & 21 & 15 & 12 \\
& $83,33 \%$ & $70 \%$ & $50 \%$ & $40 \%$ \\
TOTAL & 30 & 25 & 17 & 14 \\
\hline
\end{tabular}

Tabel 3. Distribusi responden berdasarkan alamat tempat tinggal dan hasil tinggi pada Supplementary Scales

\begin{tabular}{|c|c|c|c|c|}
\hline Alamat & $\mathrm{N}$ & PK & AAS & MAC-R \\
\hline Manado & $\begin{array}{c}23 \\
76,67 \%\end{array}$ & $\begin{array}{c}20 \\
66,67 \%\end{array}$ & $\begin{array}{c}14 \\
46,67 \%\end{array}$ & $\begin{array}{c}12 \\
40 \%\end{array}$ \\
\hline $\begin{array}{l}\text { Luar } \\
\text { Manado }\end{array}$ & $\begin{array}{c}7 \\
23,33 \%\end{array}$ & $\begin{array}{c}5 \\
16,67 \%\end{array}$ & $\begin{array}{c}3 \\
10 \%\end{array}$ & $\begin{array}{c}2 \\
6,67 \%\end{array}$ \\
\hline TOTAL & 30 & $\begin{array}{c}25 \\
83,33 \%\end{array}$ & $\begin{array}{c}17 \\
56,67 \%\end{array}$ & $\begin{array}{c}14 \\
46,67 \%\end{array}$ \\
\hline
\end{tabular}

\section{BAHASAN}

Berikut ini ialah pembahasan mengenai tiga skala Suppelementary Scales yang memiliki skor tertinggi.

\section{Post Traumatic Disorders (PK)}

Pada penelitian ini terdapat 25 responden yang memiliki psikopatologi post traumatic disorder (PK) paling tinggi. Tingginya T-skor dari skala ini mengindikasikan bahwa respoden mengalami distres emosional umum yang hebat, kecemasan dan insomnia, pikiran yang terganggu dan tidak dikehendaki. Sedangkan T-skor yang rendah mengindikasikan bahwa responden mampu beradaptasi dan tidak mengalami kecemasan. ${ }^{10}$ Pada penelitian sebelumnya yang dilakukan pada mahasiswa semester 1 Fakultas Kedokteran Universitas Sam Ratulangi dengan jumlah data valid sebanyak 101 terdapat $20,79 \%$ responden yang memiliki T-skor tinggi pada skala ini. $^{14}$

\section{Addiction Admission Scale (AAS)}

Dari 30 data valid terdapat 17 responden yang memiliki T-skor tinggi pada skala Addiction Admission Scale (AAS). Tingginya T-skor pada skala ini mengindikasikan bahwa terdapat penyalahgunaan zat. Sedangkan T-skor yang rendah mengindikasikan bahwa tidak terdapat penyalahgunaan zat. ${ }^{10}$ Pada penelitian sebelumnya terdapat 10 responden yang memiliki T-skor tinggi pada skala ini. ${ }^{14}$

\section{MacAndrew Alcoholism Scale Revised (MAC-R)}

Dari 30 data valid terdapat $46,67 \%$ responden yang memiliki T-skor tinggi. Hal ini mengindikasikan bahwa responden mungkin menyalahgunakan zat, perilaku risiko tinggi, dan memiliki sifat antisosial. T-skor yang rendah mengindikasikan adanya depresi dan kontrol diri yang berlebihan. $^{10}$ Terdapat $5,94 \%$ T-skor rendah bila dibandingkan dengan penelitian sebelumnya yang dilakukan Palempung, ${ }^{14}$ terdapat 6 responden yang memiliki T-skor tinggi dan 17 responden yang memiliki Tskor rendah.

Keterbatasan penelitian ini ialah jumlah responden terbatas 30 orang sehingga belum dapat digeneralisasikan pada kelompok besar.

\section{SIMPULAN}

Dari penelitian ini dapat disimpulkan bahwa pada 3 skala supplementary scales yang memiliki T-skor tertinggi antara lain: Post Traumatic Disorders (83,33\%), Addiction Admission Scale (56,67\%), dan MacAndrew Alcoholism Scale Revised $(46,67 \%)$. Pada penelitian ini juga dapat 
diketahui persentase terbanyak dari responden yang memiliki ketiga skala supplementary scales tertinggi ialah responden berjenis kelamin laki-laki, berpendidikan terakhir hingga SMA, dan bertempat tinggal di Manado.

\section{SARAN}

Untuk penelitian selanjutnya disarankan untuk menggunakan alat ukur psikometri lainnya dan dengan jumlah responden yang lebih banyak sehingga dapat digeneralisasikan pada kelompok besar.

\section{DAFTAR PUSTAKA}

1. Handayani PM. Hendrinato K. Motivasi anak memilih menjadi anggota komunitas punk. Artikel ilmiah hasil penelitian mahasiswa 2013. Universitas Jember. Jember. 2013 [cited 17 September 2016]. Available from:

http://repository.unej.ac.id/bitstream/ handle/123456789/59033/Panca\%20

Martha\%20Handayani.pdf?sequence= 1.

2. Pickles JM. Dari subkultur ke budaya perlawanan: Aspirasi dan pemikiran sebagian dari kaum punk/hardcore dan skinhead di Yogyakarta dan Bandung [Skripsi]. Malang: Program Acicis FISIP Universitas Muhammadiyah. [cited 17 September 2016]. Available from: http://kesos.unpad.ac.id/wpcontent/uploads/2015/12/JurnalShare-_-Vol-5-No-1_Per-Juli2015.pdf]

3. Annisa R. Wibhawa B. Apsari NC. Fenomena remaja punk ditinjau dari konsep person in environment (studi deskriptif di komunitas heaven holic kota Bandung). Bandung: Universitas Padjadjaran. Social Work Journal. 2015;5(1). [cited 17 September 2016 Available from:

http://kesos.unpad.ac.id/wpcontent/uploads/2015/12/Jurnal-

Share-_-Vol-5-No-1_Per-Juli2015.pdf].

4. Megawati N. Hubungan antara konformitas dengan perilaku agresi pada komunitas punk di kota Malang.
Universitas Brawijaya. 2014. [cited September 2016]. Available from: psikologi.ub.ac.id]

5. Maghfiroh T. Konsep diri anggota komunitas punk malang [Skripsi]. Malang: Fakultas Psikologi Universitas Islam Negeri Malang; 2007.

6. Pertumbuhan ekonomi kabupaten kota di Sulawesi Utara tahun 2011-2014. Manado dalam angka 2015. Badan Pusat Statistik Kota Manado; p. 343.

7. Widya G. Punk: Ideologi yang di salahpahami. Jakarta: Garasi house of book, 2010 [cited 25 September 2016]. Available from: http://repository.unej.ac.id/bitstream/ handle/123456789/59033/Panca\%20 Martha\%20Handayani.pdf?sequence= 1.

8. Hebdige D. Subculture: The meaning of style. [cited 25 September 2016]. Available from: www.isns.uw.edu.pl.

9. Anggraini R. The life children punk in Pekanbaru. [cited 25 September 2016]. Universitas Riau. Pekanbaru. Jurnal Online Mahasiswa FISIP. $2015 ; 2$.

10. Adams RL. Culbertson JL. Personality Assessment: Adults and Children. In: Sadock BJ, Sadock VA, editors. Kaplan and Sadock's Comprehensive Textbook of Psychiatry (8th ed). Philadelphia: Lippincot Williams and Wilkins, 2005; p.875-85.

11. Nordin H. Eisemann M, Richter J. MMPI-2 subgroups in a sample of chronic pain patients. Scand J Pyschol. 2005;46(2):209-16.

12. Arbisi PA. Butcher JN. Relationship between personality and health symptoms: use of the MMPI-2 in medical assessments. International Journal of Clinical and Health Psychology. 2004;4(3):571-95.

13. Rogers R. Sewell KW. Harisson KS. Jordan MJ. The MMPI-2 restructured clinical scales: a paradigmatic shift in scale development. Journal of Personality Assessment. 2006:87(2):139-47.

14. Palempung HG. Profil Supplementary Scales Minesota Multiphasic Personality Inventory-2(MMPI-2) Adapatasi Indonesia Pada Mahasiswa 
Ab'ror, Kairupan, Munayang: Profil supplementary scales Minnesota ...

Semester 1 Tahun Akademik

2013/2014 Fakultas Kedokteran

Universitas Sam Ratulangi Manado
[Skripsi]. Manado: Universitas Sam Ratulangi; 2014. 